\title{
Tolerability and pharmacokinetics of non-fixed and fixed combinations of artesunate and amodiaquine in Malaysian healthy normal volunteers
}

\author{
Visweswaran Navaratnam • Surash Ramanathan \\ Mohd Suhaimi Ab. Wahab • Gan Siew Hua \\ Sharif Mahsufi Mansor • Jean-René Kiechel \\ Michel Vaillant • Walter R. J. Taylor • Piero Olliaro
}

Received: 13 August 2008 / Accepted: 2 April 2009/Published online: 30 April 2009

(C) The Author(s) 2009. This article is published with open access at Springerlink.com

\begin{abstract}
Objective There is limited pharmacokinetic data available for the combination artesunate + amodiaquine, which is used widely to treat uncomplicated malaria. This study examines the bioavailability and tolerability of a fixed (200 $\mathrm{mg}$ artesunate $+540 \mathrm{mg}$ amodiaquine) and loose (200 mg+612 mg) combination with a $2 \times 2$ cross-over design in 24 healthy volunteers.

Methods Parent compounds and metabolites [dihydroartemisinin (DHA) and desethylamodiaquine (DEAQ)] were
\end{abstract}

Electronic supplementary material The online version of this article (doi:10.1007/s00228-009-0656-1) contains supplementary material, which is available to authorized users.

V. Navaratnam $\cdot$ S. Ramanathan $\cdot$ S. M. Mansor

National Center for Drug Research (CRD),

Universiti Sains Malaysia (USM),

11800 Minden,

Pulau Pinang, Penang, Malaysia

M. S. A. Wahab · G. Siew Hua

Pharmacology Laboratory,

CTU-Clinical Trial Unit,

School of Medical Sciences, Health Campus,

Hospital Universiti Sains Malaysia (HUSM),

Kubang Kerian,

Kota Bharu 16150 Kelantan, Malaysia

J.-R. Kiechel

Drugs for Neglected Diseases initiative (DNDi),

15 Chemin Louis-Dunant,

Geneva 1202, Switzerland measured by high-performance liquid chromatographyelectrochemical detection, and the area under the curve (AUC) $)_{0-t}$ and $\mathrm{C}_{\max }$ were compared by an analysis of variance (ANOVA) based on geometric least square means using the Schuirmann two one-sided test.

Results The $\mathrm{AUC}_{0-\mathrm{t}}$ for total DHA and DEAQ were $1522 \pm$ 633 and $30021 \pm 14211 \mathrm{ng} \mathrm{h} / \mathrm{ml}$ for the fixed products and $1688 \pm 767$ and $40261 \pm 19824 \mathrm{ng} \mathrm{h} / \mathrm{ml}$ (mean \pm standard deviation) for the loose products. The ANOVA showed no statistical differences except for sequence effect for DHA.

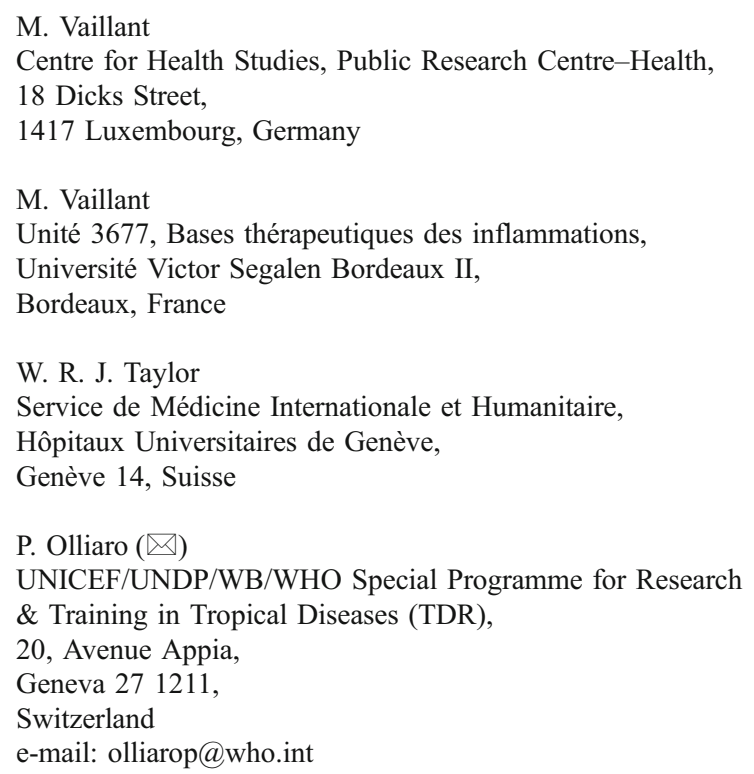


The values obtained with the fixed product were within the $125 \%$ bioequivalent limits but extend below the $80 \%$ bioequivalence limits.

Conclusion Both combinations were well tolerated and had comparable pharmacokinetic profiles; differences are unlikely to be clinically relevant.

Keywords Amodiaquine - Artesunate

Fixed combination treatment $\cdot$ Pharmacokinetics .

Non-fixed combination treatment . Tolerability

\section{Introduction}

Malaria occurs in 109 countries with 3.3 billion people at risk of contracting the disease; 247 million cases of malaria are reported annually [1]. The World Health Organisation (WHO) recommends replacing monotherapies with artemisinin combination therapies (ACTs) [2]. According to official figures, 49 million ACT courses were distributed in 2006, but real usage is likely to be much higher [1].

Artesunate (AS) combined with amodiaquine (AQ) is currently one of the most widely used ACTs and has been adopted by 20 countries worldwide (19 in Africa) as the first line treatment for malaria. Both AS and AQ are currently administered as a loose formulation or in coblister packs; however, due the large number of tablets involved, there is a possibility of patients failing to adhere to their treatment regimen or complete their course of therapy. To overcome this, a fixed-dose combination treatment (AS/AQ) that provides a simplified regimen has been developed and registered.

Artesunate and AQ have independent but complementary modes of action: the former is a short-lived, highly potent artemisinin that provides a rapid reduction of parasite biomass, whereas the latter has a longer half-life to ensure the eradication of residual parasites [3]. Artesunate [dihydroartemisinin-10 $\alpha$-hemisuccinate, molecular weight (MW) 384] is considered to be a prodrug, as it is rapidly and extensively converted via chemical and enzymatic pathways to its main bioactive metabolite, dihydroartemisinin (DHA; also referred to as artenimol, MW 284). Following oral intake, AS levels are transient, and DHA is the predominant species; the two moieties are roughly equipotent [4], and both contribute to parasite killing. The pharmacology of AS and DHA, following oral administration of AS, show considerable inter-individual variation and are affected by disease status $[5,6]$. The elimination half-life $\left(t_{1} / 2\right)$ of DHA averages $0.65-2.59 \mathrm{~h} \mathrm{[7}$, 8]. Amodiaquine is also considered to be a prodrug and is rapidly and extensively converted to its main metabolite, $N$ desethylamodiaquine (DEAQ), essentially in the liver by cytochrome P 2C8 (CYP2C8) [9]. Unlike AS, AQ has a negligible effect on parasites. In adults, the elimination half-life of AQ is approximately $4 \mathrm{~h}$ [10], but DEAQ has a much longer but variable half-life (2.5-18.2 days) [11, $12]$.

The pharmacology of oral AS, often co-administrated with mefloquine, has been studied in both healthy volunteers and malaria patients. In contrast, despite years of widespread use either alone or combined with AS, pharmacological information on AQ is inadequate.

The aim of this study was to investigate the pharmacokinetic properties, tolerability, and bioavailability of AS and AQ when co-administered as either fixed or non-fixed products in healthy normal volunteers.

\section{Methods}

Study design

This was an open, randomised, two-period crossover trial in which the PK properties, tolerability and bioavailability of AS + AQ when administered as a fixed-dose or non-fixed dose preparation were compared. The study was conducted in accordance with international Good Clinical Practice standards and monitored. The protocol was approved by the Institution Ethical Review Board of the Teaching Hospital Universiti Sains Malaysia, Kota Bharu, Malaysia and the WHO Ethics Committee, and was authorised by the Malaysian Ministry of Health.

A total of 24 healthy normal volunteers (HNVs), aged between 21 and 45 years, were randomised to receive either the non-fixed (NF) or the fixed (F) combination regimen during Study Period 1. The randomisation process was carried out by using a table of random numbers to select 24 consecutive, unduplicated numbers between 01 and 24. After a wash-out period of 60 days $\left(5 \times t_{1 / 2}\right.$ DEAQ 45-90 days), subjects entered Study Period 2 and were given the alternative treatment combination. Thus, one group of subjects received the fixed, followed by the non-fixed combination (F-NF), while the other group received the non-fixed, followed by the fixed product $(\mathrm{NF}-\mathrm{F})$.

Drugs were administered under fasting conditions. Each subject received a single total dose of $200 \mathrm{mg}$ AS plus $540 \mathrm{mg}$ AQ when given the fixed product, and $200 \mathrm{mg}$ AS plus $612 \mathrm{mg}$ AQ with the non-fixed product. These doses represent 1 day of a 3-day therapeutic course and were selected to be as close as possible to the target treatment doses of 4 and $10 \mathrm{mg} \mathrm{kg}^{-1}$ day $^{-1}$ for $\mathrm{AS}$ and $\mathrm{AQ}$, respectively. The doses of AQ in the fixed and non-fixed formulations were different because of the different strengths of the formulations used. 
Study drugs

The fixed-dose co-formulated product (manufactured by Creapharm, France, batch no. CPM 5856) consisted of $100 \mathrm{mg} \mathrm{AS}$ and $270 \mathrm{mg}$ AQ base; the loose non-fixed product consisted of AS (Arsumax $50 \mathrm{mg}$ tablets; SanofiAventis, Paris, France/Guilin Pharma Co, China, batch no. 31201) and AQ (Flavoquin $153 \mathrm{mg}$ of AQ base; Hoechst Marion Roussel, Sanofi-Aventis, batch no. 4).

\section{Entry criteria}

Volunteers were recruited by means of advertisements placed at the teaching hospital of the Universiti Sains Malaysia, Kota Bahru. Written informed consent was required before the volunteers were allowed to participate in the trials. Entry criteria included a negative pregnancy test for women; a negative malaria thick smear; no significant abnormal findings on the medical history or clinical examination (including electrocardiogram, haematology, liver and renal function tests); no history of antimalarial treatment in the preceding 2 months; no other drugs or medications in the preceding week; adequate venous access; no abuse of alcohol or recreational drugs; no known allergy to the study drugs; smokers ( $>10 /$ day) were also excluded.

\section{Drug assay}

\section{Sampling}

Blood samples were collected at pre-dose, at $0.25,0.5$, $0.75,1,1.5,2,3,4,6,8,12,24,48$ and $72 \mathrm{~h}$ postmedication and at $5,7,14,21,28,35,42$ and 60 days postmedication. Day 60 for Study Period 1 and Day 0 for Study Period 2 coincided. Specimens in the first $12 \mathrm{~h}$ of each study period were drawn via an indwelling catheter; for the remaining periods, blood samples were drawn by direct venipuncture. Blood samples $(5 \mathrm{ml}$ each) were stored in heparinised vacutainer tubes for further processing. The levels of AQ and DEAQ were measured at all time points, while those of AS and DHA were measured at pre-dose and at $0.25,0.50,0.75,1.0,1.5,2,3,4,6,8$ and $12 \mathrm{~h}$ after drug administration. After centrifugation of blood samples, the plasma samples were immediately transferred to separate, appropriately labelled plastic cryotubes and frozen at $-70^{\circ} \mathrm{C}$.

\section{Analytical methods}

The assays were carried out at the Centre for Drug Research, Universiti Sains Malaysia, Penang, Malaysia.
Artesunate and dihydroartemisinin This assay method was validated with minor modifications of a previously published method [13]. The analyses of AS and DHA were carried out on BAS 200A high-performance liquid chromatography/electrochemical (HPLC-EC; BAS, West Lafayette, IN) systems operating at reductive mode. Chromatographic separation of AS, DHA and the internal standard artemisinin (QHS) was obtained at room temperature $\left(25^{\circ} \mathrm{C}\right)$ on an Inertsil $\mathrm{C} 4$ column (internal diameter $150 \times 4.6 \mathrm{~mm}$, particle size $5 \mu \mathrm{m}$; GL Sciences, Tokyo, Japan). The mobile phase consisted of acetonitrile (ACN) and $0.05 M$ acetic acid (40:60 \%v/v) adjusted to $\mathrm{pH} 4.0$ with $1 \mathrm{M} \mathrm{NaOH}$. The flow rate was $1.50 \mathrm{ml} / \mathrm{min}$. Detection was performed in the reductive mode at $-1000 \mathrm{mV}$ in an oxygen-free environment. The HPLC-EC (reductive) system produced a linear response for the concentration of AS and DHA varying from 20 to $1600 \mathrm{ng} / \mathrm{ml}$ respectively. The extraction recoveries of AS, DHA and QHS were above $79 \%$ with a coefficient of variation (CV) not exceeding $13 \%$. The lower limit of quantification (LLOQ) of AS was $20 \mathrm{ng} / \mathrm{ml}$, and its accuracy and CV were -0.1 and $4.4 \%$, respectively; the corresponding values for DHA (LLOQ $20 \mathrm{ng} / \mathrm{ml}$ ) were -2.6 and $6.0 \%$, respectively. The withinday and day-to-day precision for both AS and DHA at low, medium and high concentrations did not exceed 15\%.

Amodiaquine and $\mathrm{N}$-desethylamodiaquine The analyses of AQ and DEAQ were carried out on BAS 200A HPLC-EC systems coupled to an EC detector operating at oxidative mode. The analysis of AQ, DEAQ and the IB-DEAQ (internal standard) was carried out at room temperature $\left(25^{\circ} \mathrm{C}\right)$ using an Inertsil C4 column (internal diameter $150 \times$ $4.6 \mathrm{~mm}$, particle size $5 \mu \mathrm{m}$; GL Sciences). The mobile phase consisted of ACN and $0.05 M \mathrm{KH}_{2} \mathrm{PO}_{4}(11: 89, \% \mathrm{v} / \mathrm{v})$ adjusted to $\mathrm{pH} 4.0$ with orthophosphoric acid. The flow rate was $1.0 \mathrm{ml} / \mathrm{min}$. Detection was performed in the oxidative mode at $+800 \mathrm{mV}$. The extraction recoveries of AQ, DEAQ and IB-DEAQ were all above $80 \%$, with a CV of less than $11 \%$. The HPLC-EC (oxidative) system produced a linear response for the concentration of AQ and DEAQ that varied from 20 to $1600 \mathrm{ng} / \mathrm{ml}$, respectively. The LLOQ of AQ and DEAQ were $20 \mathrm{ng} / \mathrm{ml}$, and the accuracy and variation were of 4.2 and $5.0 \%$, respectively; the $\mathrm{CV}$ were 7.5 and $7.3 \%$, respectively. The within-day and day-to-day precision for both AQ and DEAQ were less than $15 \%$.

\section{Pharmacokinetic analyses}

We measured the parent drug and main active metabolite of both compounds (AS + DHA and AQ + DEAQ). In addition, the total DHA concentration was estimated by summation of HPLC-determined DHA and DHA equiva- 
lence of the corresponding plasma sampling times of AS for each individual. The DHA equivalence was determined by converting the drug concentration of AS to DHA stoichiometrically. The pharmacokinetic parameters $\mathrm{C}_{\max }, \mathrm{T}_{\max }$, and $\mathrm{AUC}_{0-\mathrm{t}}$ were determined using model independent formulae [14]. Maximum achieved concentration $\left(\mathrm{C}_{\max }\right)$ and time to achieve the maximum concentration $\left(\mathrm{T}_{\max }\right)$ were obtained from a visual inspection of the plasma concentration versus time curve. Area under the concentrationtime curve from 0 to $\mathrm{t}\left(\mathrm{AUC}_{0-\mathrm{t}}\right.$, where $\mathrm{t}=$ last quantifiable drug concentration) was calculated using the linear trapezoidal rule: $\mathrm{AUC}_{0-\mathrm{t}}=\left[\left(\mathrm{C}_{1}+\mathrm{C}_{2}\right) / 2\left(\mathrm{t}_{2}-\mathrm{t}_{1}\right)\right]+\ldots . .+\left[\left(\mathrm{C}_{\mathrm{n}-1}+\mathrm{C}_{\mathrm{n}}\right) /\right.$ $\left.2\left(t_{n}-t_{n-1}\right)\right]$. The $\mathrm{AUC}_{0-\infty}$ (up to infinity) was calculated by the formula $\mathrm{AUC}_{0-\mathrm{t}}+\mathrm{Ct} / \lambda \mathrm{z}$ where $\mathrm{Ct}$ is the concentration at the last quantifiable time. From the terminal log-linear (disposition) phase, a first order elimination rate constant $(\lambda z)$ was estimated by linear regression and terminal halflife value $\left(t_{1 / 2}\right)$ was estimated from at least three concentration values using the equation $\left(t_{1 / 2}\right)=\ln 2 / \lambda z$. The mean residence time (MRT) was calculated for both parent compounds and metabolites as the AUMC/AUC where AUMC is the area under the first moment-versus-time curve.

\section{Bioavailability}

For bioequivalence studies, the 1992 Federal Drug Agency (FDA) guidance recommends that the statistical analysis for pharmacokinetic measures, such as AUC and $\mathrm{C}_{\max }$, be based on the two one-sided tests procedure that examines whether the average values for the pharmacokinetic measures determined after administration of the test and reference products were comparable. This approach is termed average bioequivalence and involves the calculation of a $90 \%$ confidence interval (CI) for the ratio of the averages (population geometric means) of the measures for the test and reference products. To establish bioequivalence, the calculated confidence interval should fall within a limit, usually between 80 and $125 \%$, for the ratio of the product averages [16]. This method is equivalent to the corresponding two one-sided tests procedure with the null hypothesis of bioinequivalence at the $5 \%$ significance level [17].

Bioavailabilities of the fixed and non-fixed AS/AQ formulations were compared using mean $\mathrm{AUC}_{0-\mathrm{t}}$. In addition, we tested the $\mathrm{C}_{\max }, \mathrm{t}_{\max }$ and $\mathrm{t}_{1 / 2}$. Differences in the $\ln$ mean $\mathrm{AUC}_{0-\mathrm{t}}$ and $\ln$ mean $\mathrm{C}_{\max }$ between treatment periods were compared using analysis of variance (ANOVA). The model allowed for the effects of formulation, period, sequence and subjects within sequence on the observed parameter.

For $\mathrm{AUC}_{0-\mathrm{t}}$ and $\mathrm{C}_{\max }$, we applied the Schuirmann's two one-sided tests (TOST) to compute the probability to reject the null hypothesis (i.e. that the two products are different). The $T_{\max }$ and $t_{1 / 2}$ values were compared by the Wilcoxon signed rank test. All statistical analyses were performed with the statistical software package EquivTest ver. 2.0 [15].

\section{Safety}

We used standard definitions for adverse events (AEs) and serious adverse events (SAEs). All subjects were assessed clinically at baseline. Reporting of symptoms was solicited during the course of the study. Clinical AEs were described by the attending physician in terms of signs and symptoms and classed by body system: gastrointestinal (GI), cardiovascular (CVS), central nervous system (CNS), etc. They were assessed for severity [mild (Grade 1), moderate (Grade 2), severe (Grade 3), very severe (Grade 4)] using the Common Toxicity Criteria (CTC V3.0; National Institute of Health, Bethesda, MD).

Laboratory examinations (haematology, liver and renal functions) were conducted at Day 0, Day 7 and Day 28 of each study period. Twelve lead electrocardiograms (ECGs) were performed at baseline and at 1, 2, 4, and $24 \mathrm{~h}$ postdrug administration; this was repeated for Study Period 2 (results to be reported in a separate analysis). All AEs that occurred during the study were recorded with the date and time of occurrence and the date the abnormal finding disappeared.

The chi-squared test was used to compare the frequencies of: (1) AEs between groups and (2) normal/abnormal laboratory values in shift tables. The Cochran-MantelHaentzel statistic was used to assess the general association of the treatment groups and the occurrence of at least one $\mathrm{AE}$ in a subject during the two study periods.

\section{Results}

Disposition and baseline characteristics

Study subject disposition is shown in Fig. 1. Two subjects were excluded from the overall data analysis: one subject received only the non-fixed AS/AQ combination in Study Period 1, but was later withdrawn from the study because of acute gouty arthritis (this event was a recrudescence of prior disease that was judged to be probably related to the study drug); the other subject had an extraordinarily high DEAQ AUC ${ }_{0-\mathrm{t}}$ (approx. ten10-fold higher than that with the fixed combination) after having received the non-fixed combination. This observation was deemed to be an unexplainable outlying result, and all pharmacokinetic data pertaining to this subject were excluded from the analyses. The threshold for outliers was calculated as recommended 


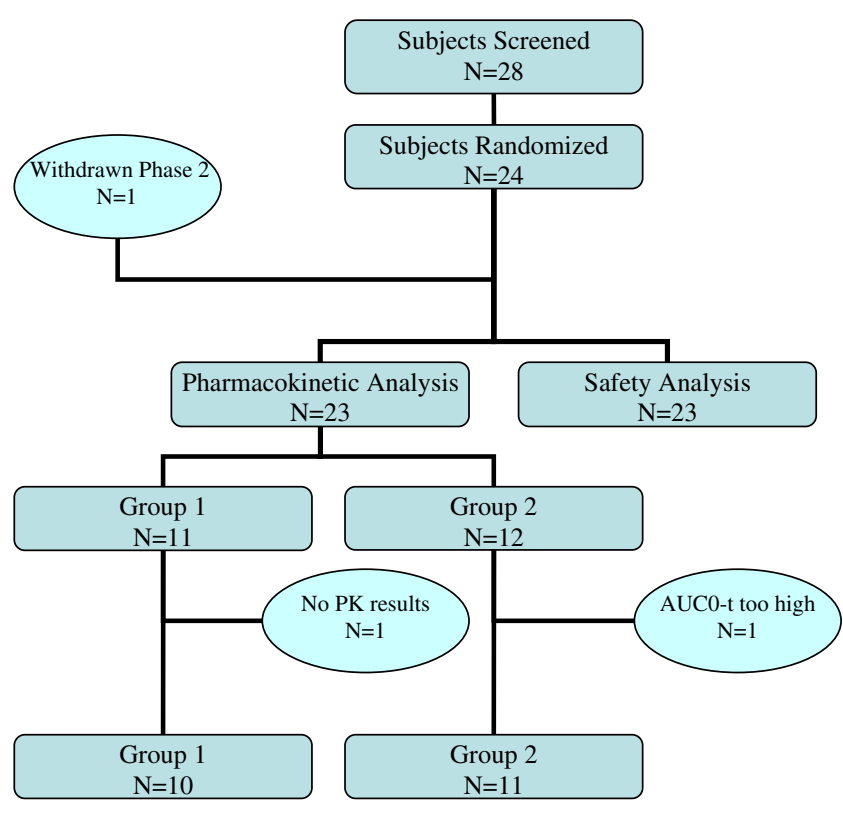

Fig. 1 Profile of study subject disposition

for skewed distributions from the interquartile range. Inclusion of this subject's data in the analyses did not alter any bioequivalence conclusions (data not shown). Therefore, 23 of the original 24 subjects were analysed for drug disposition (six males, 17 females) and 22 for comparative bioavailability.

The mean age of the subjects was $27.3 \pm 6.8$ years. Medical history and vital signs were similar in the two groups except pulse rate $(p=0.02)$.

Pharmacokinetics

After oral administration, AS and AQ were rapidly absorbed and underwent rapid and extensive metabolism to their respective metabolites, DHA and DEAQ. The plasma levels of both DHA and DEAQ were manifold higher and persisted for longer than their respective parent compounds. The pharmacokinetic properties of AS, DHA, $\mathrm{AQ}, \mathrm{DEAQ}$ and total DHA are given in Table 1; the plasma time-concentration profiles of AS, DHA, AQ and DEAQ are shown in Fig. 2.

The relative bioavailabilities of total DHA and DEAQ expressed as $\mathrm{AUC}_{0-\mathrm{t}}$ produced by the fixed product were similar to those of the non-fixed product (F:NF ratios 102.3 and $107 \%$, respectively). The analysis of comparative bioavailability of the two products is shown in Table 2 . There was no evidence of carry-over effects between subjects except for the AQ (parent) AUC, no period effect except for total DHA AUC and no drug effects within subjects between the two formulations except a marginal effect for AQ and DEQA AUC. For both total DHA and DEAQ, the $\mathrm{AUC}_{0-\mathrm{t}}$ values obtained with the fixed

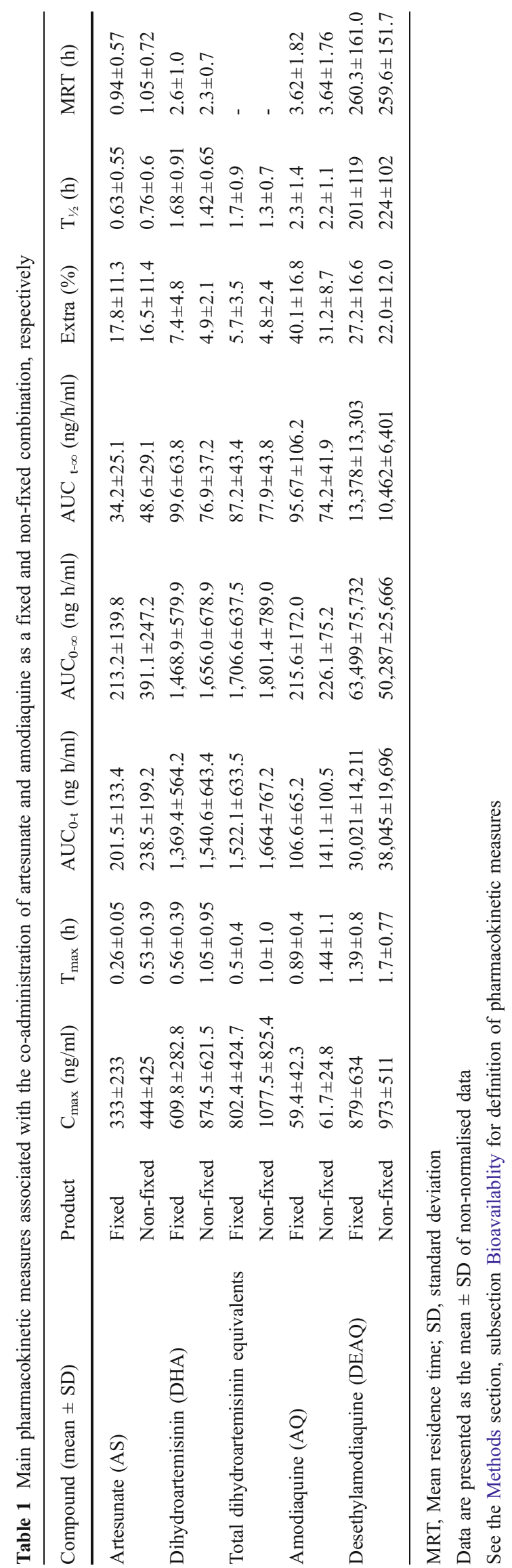


Fig. 2 Concentration-time profiles of artesunate $(A S)$ /dihydroartemisinin $(D H A)$ (a) and amodiaquine $(A Q)$ /desethylamodiaquine (DEAZ) (b). Filled diamonds Fixed product, open boxes non-fixed product
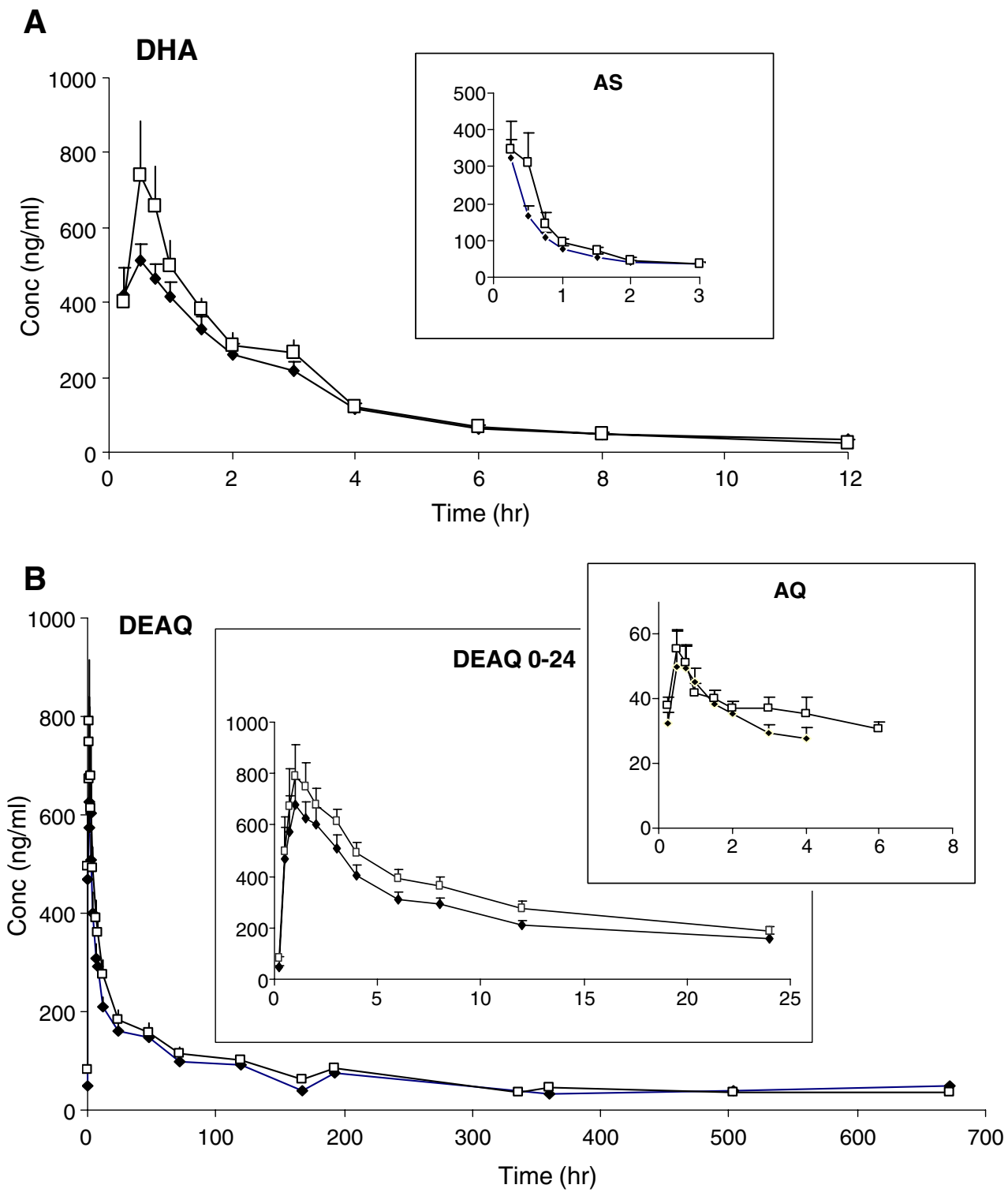

combination lie within the $95 \%$ CI of the non-fixed products [data not shown: provided as Electronic Supplementary Material (ESM)]. The values produced by the fixed product appear to be tighter than those provided by the nonfixed product for both total DHA and DEAQ (data not shown: provided as ESM).

Based on the $90 \% \mathrm{CI}$ of the geometric least squares means ratios (GLSMR), the $\mathrm{C}_{\max }$ and $\mathrm{AUC}_{0-\mathrm{t}}$ values produced with the fixed combination with respect to the non-fixed combination were within the upper boundary (125\%) but extended beyond the lower boundary $(80 \%)$ of the confidence interval for all moieties except AS $\mathrm{C}_{\max }$, which was also $>125 \%$ (Table 2). The Shuirmann TOST was non-significant for lower limits, while the upper limits of the one-tailed $t$-statistics were significant (again except for $\mathrm{AS} \mathrm{C}_{\max }$ ) (Table 2). Plasma $\mathrm{C}_{\max }$ and $\mathrm{AUC}_{0 \text {-t }}$ of total DHA were lower in the fixed combination by 12 and $8 \%$, respectively, for total DHA and by 15 and $14 \%$, respectively, for DEAQ. The $\mathrm{T}_{\max }$ was significantly shorter in subjects given the fixed product for total DHA, AS and DHA, longer for AQ and not different for DEAQ (Table 2). The within-subject variation $(\% \mathrm{CV})$ of the $\mathrm{AUC}_{0-\mathrm{t}}$ between the non-fixed and the fixed combination were $4.3 \%$ for total DHA and $3.6 \%$ for DEAQ. The $t_{1 / 2}$ for both formulations was not bioequivalent (Table 2).

Mean residence times (see Table 1) were compared between the fixed and non-fixed combination for AS, DHA, AQ and DEAQ using a $t$ test. The comparisons were found to be non-significant. The mean \pm standard deviation AUC ratios AS:DHA were $0.08 \pm 0.12$ and $0.09 \pm 0.06$ for the fixed and non-fixed product, respectively; the corresponding values for AQ:DEAQ were $0.002 \pm 0.002$ and $0.003 \pm 0.004$, respectively, with no difference between the two formulations. 
Table 2 Comparative bioavailabilities of fixed and non-fixed combinations of artesunate and amodiaquine. Combinations are measured as total DHA and DEAQ

\begin{tabular}{|c|c|c|c|c|c|c|c|c|c|c|}
\hline \multirow[t]{2}{*}{ Compound } & \multirow[t]{2}{*}{ Pharmacokinetic measure } & \multicolumn{4}{|l|}{ ANOVA } & \multicolumn{4}{|l|}{ GLSM } & \multirow{2}{*}{$\begin{array}{l}\text { Schuirmann TOST } \\
\text { L/U } p \text {-value }\end{array}$} \\
\hline & & Carry-over & Period & Drug & $\mathrm{CV}(\%)$ & Fixed & Non-fixed & Ratio & $90 \% \mathrm{CI}$ & \\
\hline \multirow[t]{4}{*}{ Total DHA } & $\mathrm{AUC}_{0-\mathrm{t}}(\mathrm{ng} \mathrm{h} / \mathrm{ml})$ & 0.56 & 0.02 & 0.38 & 4.31 & 1398.3 & 1522.2 & 0.9 & $0.79,1.08$ & $0.08 / 0.002$ \\
\hline & $\mathrm{C}_{\max }(\mathrm{ng} / \mathrm{ml})$ & 0.63 & 0.23 & 0.28 & 8.7 & 714.8 & 870.4 & 0.8 & $0.60,1.12$ & $0.44 / 0.01$ \\
\hline & $\mathrm{T}_{\max }^{\mathrm{a}}(\mathrm{h})$ & & & & & 0.53 & 1.03 & 0.51 & & 0.03 (Wilcoxon) \\
\hline & $\mathrm{T}_{1 / 2}(\mathrm{~h})$ & 0.78 & 0.93 & 0.13 & 130.56 & 1.49 & 1.25 & 1.19 & $0.98,1.45$ & $0.002 / 0.34$ \\
\hline \multirow[t]{4}{*}{ AS } & $\mathrm{AU}_{\mathrm{C} 0-\mathrm{t}}(\mathrm{ng} \mathrm{h} / \mathrm{ml})$ & 0.53 & 0.12 & 0.63 & 8.85 & 168.04 & 182.4 & 0.92 & $0.72,1.17$ & $0.17 / 0.0224$ \\
\hline & $\mathrm{C}_{\max }(\mathrm{ng} / \mathrm{ml})$ & 0.46 & 0.19 & 0.91 & 11.89 & 281.08 & 291.96 & 0.96 & $0.67,1.38$ & $0.1923 / 0.1123$ \\
\hline & $\mathrm{T}_{\max }^{\mathrm{a}}(\mathrm{h})$ & & & & & 0.26 & 0.55 & 0.47 & & 0.005 (Wilcoxon) \\
\hline & $T_{1 / 2}(h)$ & 0.47 & 0.80 & 0.75 & -175.12 & 0.48 & 0.59 & 0.81 & $0.27,2.38$ & $0.49 / 0.23$ \\
\hline \multirow[t]{4}{*}{ DHA } & $\operatorname{AUC}_{0-\mathrm{t}}(\mathrm{ng} \mathrm{h} / \mathrm{ml})$ & 0.85 & 0.07 & 0.24 & 8.51 & 1257.12 & 1430.97 & 0.878 & $0.73,1.06$ & $0.198 / 0.0019$ \\
\hline & $\mathrm{C}_{\max }(\mathrm{ng} / \mathrm{ml})$ & 0.97 & 0.14 & 0.10 & 8.70 & 550.35 & 736.52 & 0.74 & $0.56,1.00$ & $0.6542 / 0.0032$ \\
\hline & $\mathrm{T}_{\max }^{\mathrm{a}}(\mathrm{h})$ & & & & & 0.56 & 1.07 & 0.52 & & 0.06 (Wilcoxon) \\
\hline & $T_{1 / 2}(h)$ & 0.93 & 0.78 & 0.29 & 102.14 & 1.47 & 1.32 & 1.11 & $0.94,1.31$ & $0.002 / 0.11$ \\
\hline \multirow[t]{4}{*}{ AQ } & $\mathrm{AUC}_{0-\mathrm{t}}(\mathrm{ng} \mathrm{h} / \mathrm{ml})$ & 0.03 & 0.43 & $0.0415^{*}$ & 8.60 & 97.34 & 136.75 & 0.71 & $0.54,0.94$ & $0.761 / 0.0018$ \\
\hline & $\mathrm{C}_{\max }(\mathrm{ng} / \mathrm{ml})$ & 0.06 & 0.74 & 0.28 & 8.87 & 53.89 & 63.69 & 0.85 & $0.71,1.03$ & $0.26 / 0.0012$ \\
\hline & $\mathrm{T}_{\max }^{\mathrm{a}}(\mathrm{h})$ & & & & & 0.85 & 1.62 & 0.52 & & 0.04 (Wilcoxon) \\
\hline & $\mathrm{T}_{1 / 2}(\mathrm{~h})$ & 0.64 & 0.34 & 0.16 & 41.62 & 1.42 & 2.60 & 0.55 & $0.24,1.24$ & $0.85 / 0.05$ \\
\hline \multirow[t]{4}{*}{ DEAQ } & $\mathrm{AUC}_{0-\mathrm{t}}(\mathrm{ng} \mathrm{h} / \mathrm{ml})$ & 0.63 & 0.45 & 0.05 & 3.64 & 26630 & 35000 & 0.8 & $0.6,0.9$ & $0.65 / 0.0003$ \\
\hline & $\mathrm{C}_{\max }(\mathrm{ng} / \mathrm{ml})$ & 0.45 & 0.1 & 0.17 & 5.32 & 749.1 & 872.7 & 0.9 & $0.7,1.0$ & $0.26 / 0.001$ \\
\hline & $\mathrm{T}_{\max }(\mathrm{h})$ & & & & & 1.39 & 1.68 & 0.83 & & 0.14 (Wilcoxon) \\
\hline & $\mathrm{T}_{1 / 2}(\mathrm{~h})$ & 0.08 & 0.92 & 0.60 & 14.46 & 159.03 & 188.09 & 0.84 & $0.49,1.45$ & $0.43 / 0.11$ \\
\hline
\end{tabular}

GLSM, Geometric least squares mean; CI, confidence interval; CV, coefficient of variance

Numbers under carry-over, period and drug are $p$ values. Values in the Fixed and Non-fixed columns are means

${ }^{a}$ Comparison by arithmetic means and Wilcoxon test (non-parametric approach)

When individual subjects were considered, there was no consistent direction of change in any parameter measured. Figure 3 depicts individual data with the two products of $\mathrm{AUC}_{0-\mathrm{t}}$ for total DHA and DEAQ. The ranges of values were similar for the fixed and non-fixed combination, and changes went both ways between the two combinations: for DHA and DEAQ, values increased in 46 and $35 \%$ of patients, respectively, and decreased in 54 and $65 \%$, respectively.

Safety

Both formulations were tolerated. Overall, 42 events were reported. During Study Periods 1 and 2, 45 and 55\% of subjects had at least one AE. By drug group, the proportions were: (1) 67 (F) versus 36\% (NF) in Study Period 1, and (2) 45 (F) versus 58\% (NF) in Study Period 2.

There was no statistically significant difference between sequences (62 and $41 \%$ of subjects in the F-NF and NF-F sequences had at least one $\mathrm{AE}, p=0.14)$ or between Study Period 1 and $2(p=1.0)$. The Cochran-Mantel-Haentzel statistic for a general association of the treatment groups and the occurrence of at least one $\mathrm{AE}$ in a subject during the two periods of the study showed no significant difference $(p=0.56)$

The most common AEs were liver enzyme abnormalities ( $21 \%$ of all AEs), flushing (17\%), dizziness and giddiness (14\% each) and nausea (7\%); all other events contributed $<5 \%$. The body systems most commonly affected were the gastro-intestinal system (35\% of AEs including liver enzyme abnormalities) and the central and peripheral nervous system ( $30 \%$ of all AEs).

There was no significant difference in the drug-event relationship between the two groups: 10/23 events in Group 1 and $13 / 20$ in Group 2 were judged to be probably or definitely related to study drug (43 and 65\%, respectively).

The main laboratory parameters monitored during the study are presented in Table 3. At screening, 18 subjects had mildly abnormal laboratory values (Grade 1) and one subject exhibited a Grade 2 alanine transaminase (ALT) concentration. Pre-treatment, there was one case of Grade 1 neutropaenia $\left(1600 \times 10^{6} / 1\right)$ in the group that received the non-fixed combination first; this subject returned to normal by Day 7 of Study Period 1. One subject was inadvertently 
Fig. 3 Stick plots of the area under the concentration-time curve from time zero to last quantifiable measurement $\left(\mathrm{AUC}_{0-\mathrm{t}}\right)$ of total DHA (a), AS (b), DHA (c), AQ (d) and DEAQ (e) of the fixed versus non-fixed products for individual subjects (numbers)
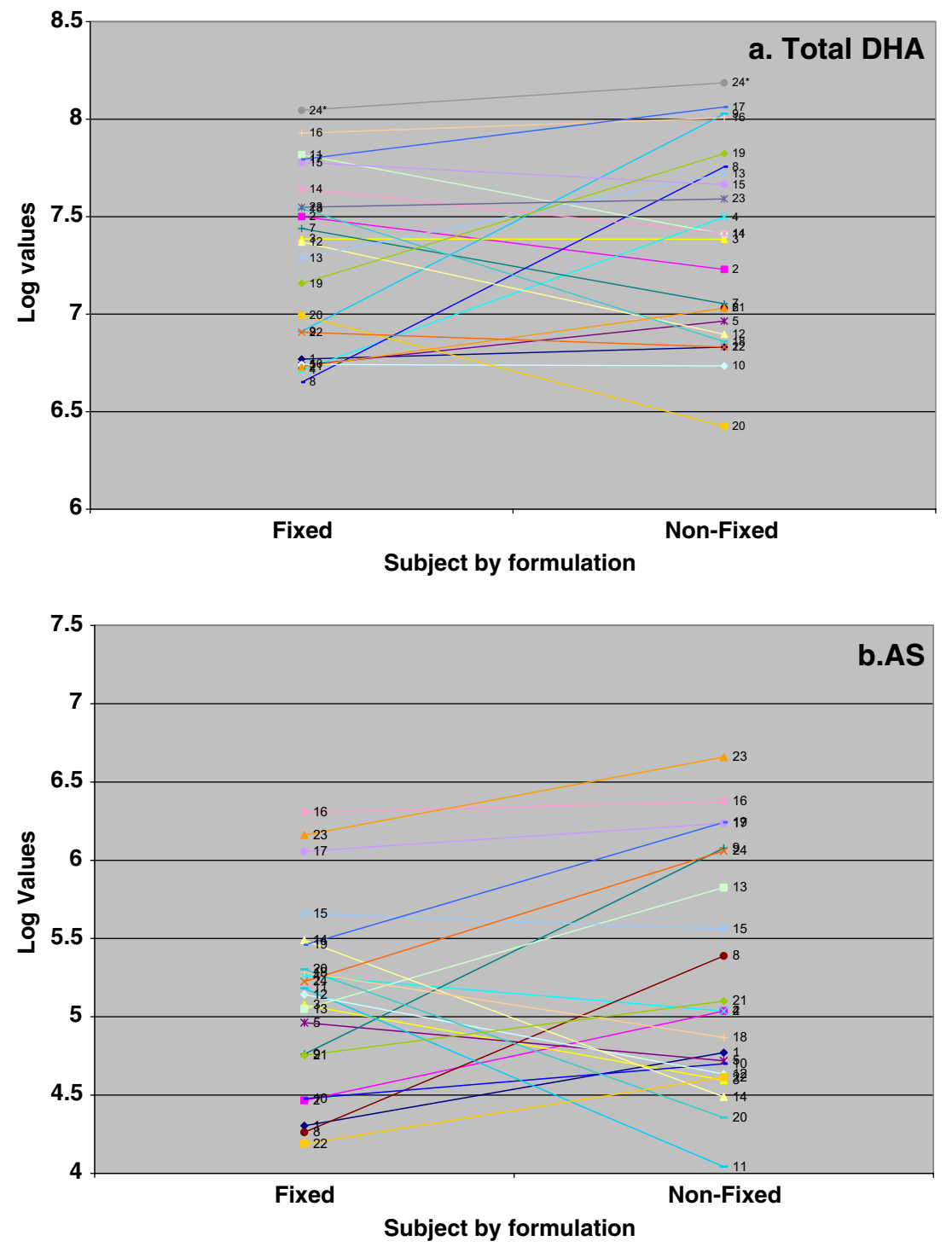

enrolled with a Grade 2 baseline value of ALT; this also normalised during follow-up.

Four subjects presented five abnormal laboratory values during the study: three were Grade 3 and two were Grade 4. One subject with a baseline uric acid value of $546 \mu \mathrm{moll} / 1$ experienced two episodes of Grade 4 (uric acid > $590 \mu \mathrm{moll} / \mathrm{l})$ elevation in uric acid at Day 7 and 29 of Study Period 1, with values of $598 \mu \mathrm{moll} / 1$ and $636 \mu \mathrm{moll} / 1$, respectively. This patient had a history of gout arthritis and was withdrawn from the study after Study Period 1.

Three individuals had one Grade 3 deviation each: (1) $\mathrm{ALT}=156 \mathrm{U} / \mathrm{L}(5-20 \times$ upper normal limit $)$ at Day 60 of Study Period 2 (sequence NF-F); (2) hypocalcaemia calcium $=1.67 \mathrm{mmol} / \mathrm{l}(1.5-1.75 \times$ upper limit) (sequence NF-F); (3) hyponatraemia sodium $=124 \mathrm{mmol} / \mathrm{l}(120-130 \times$ upper limit) at Day 7 of Study Period 1. No volunteers developed neutropaenia during follow-up.
No serious AEs occurred. One subject was withdrawn due to an exacerbation of pre-existing gout which had not been declared or detected on recruitment. The subject was treated with non-steroidal anti-inflammatory drugs and ultimately recovered.

\section{Discussion}

The results of this study on adult Malaysian healthy volunteers using a cross-over design shows that AS and AQ are readily absorbed and well tolerated when co-administered either as loose products (in a non-fixed combination) or as a fixed-dose combination. However, the two combinations cannot strictly be defined as "bioequivalent".

We measured and reported the disposition of the parent compounds and their metabolites separately, but we 
Fig. 3 (continued)
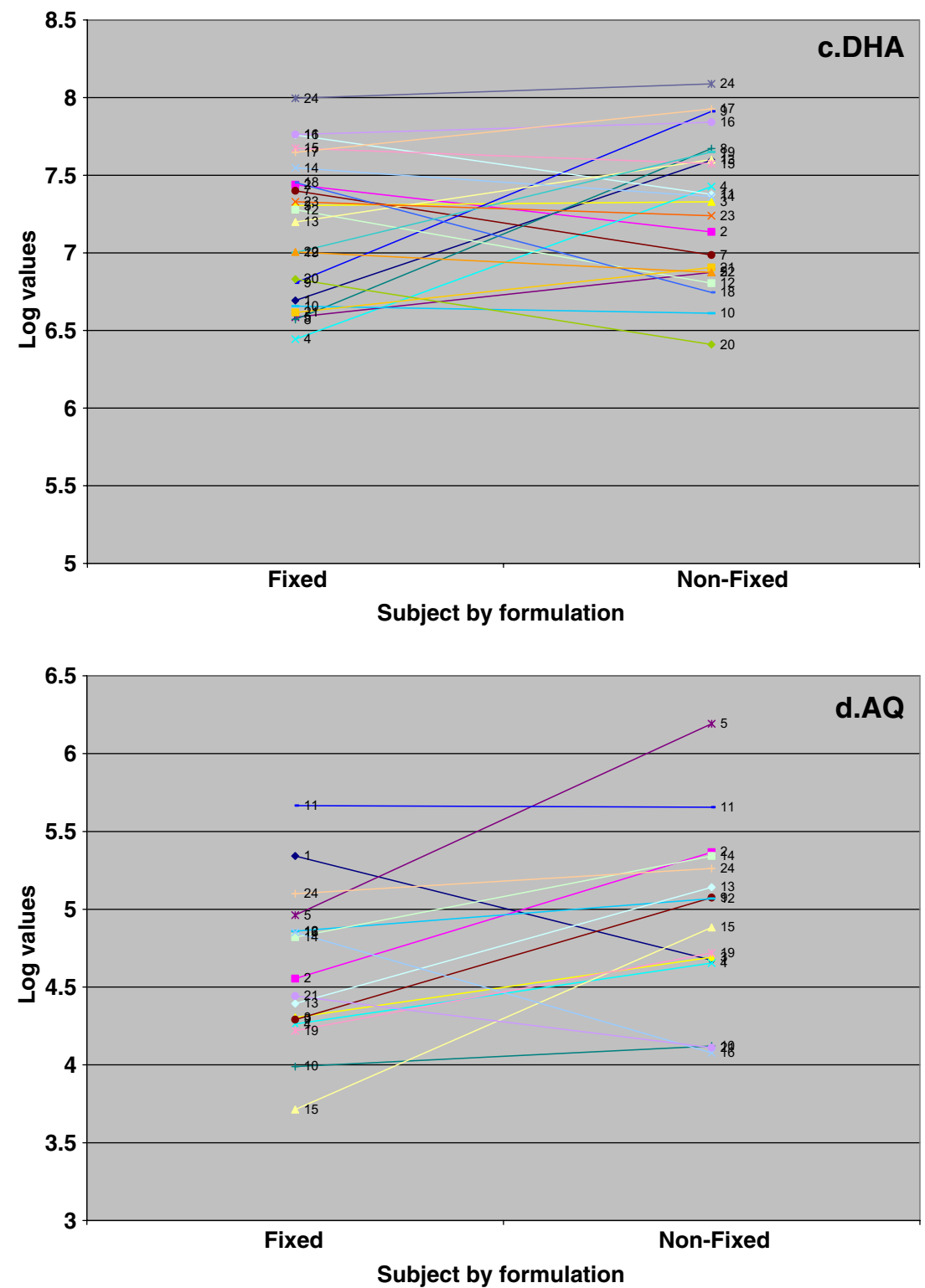

considered the primary analytes (total DHA for AS, and DEAQ for AQ), as the biologically and clinically relevant indicators of drug absorption. For AS and DHA, the reason for combining the two measurements (after stoichiometrical conversion of the measured AS values) is that the two compounds have comparable antimalarial potencies [4] and conversion of AS to DHA is rapid (chemical hydrolysis starts in the stomach). This makes their pharmacological effects indistinguishable over their very short residence time. This approach is supported by the correlation between the bioassay and the measurement of the two separate products [18], the combined measurement may be the better parameter to use for pharmacokinetic-pharmacodynamic analyses. Although AQ is more potent in vitro than its metabolite, the systemic exposure to AQ is considerably lower than that to DEAQ [10, 12], which is solely responsible for sustained antimalarial activity after AS/ DHA have been eliminated. The ratio between the AUCs of AS to DHA and AQ to DEAQ was approximately $8.5 \%$ and $0.02 \%$, respectively; the AQ $t_{1 / 2}$ was one tenth of that for DEAQ.

In this study we used different descriptive and statistical approaches to assess and compare the product bioavailabilities, and these generally gave consistent results. It is commonly accepted that the two primary parameters used for measuring the extent of drug absorption are area under the curve (AUC) and maximum concentration $\left(\mathrm{C}_{\max }\right)$, both logarithmically transformed. To confirm bioequivalence of the two products, the geometric mean ratios (plus 90\% CI) of these metrics should lie within an $80-125 \%$ window of acceptance [16]. We used the ANOVA $F$ test to identify the source of variance, be it a product, subject or period effect. 
Fig. 3 (continued)

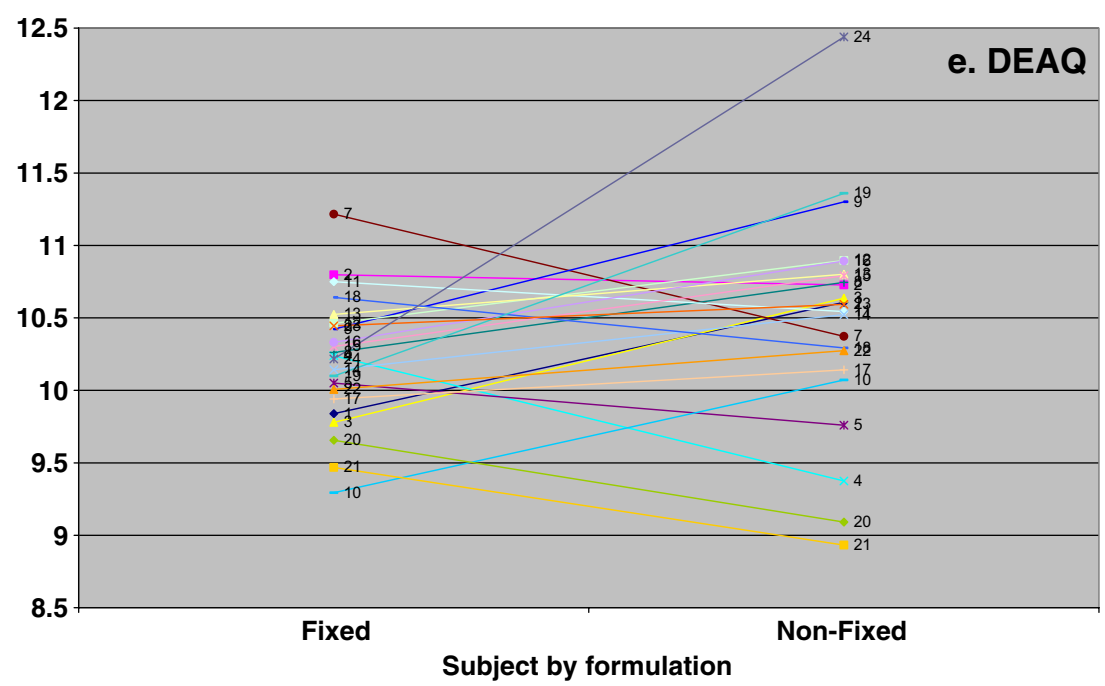

Table 3 Laboratory parameter measures by product over time

\begin{tabular}{|c|c|c|c|c|c|c|c|c|c|}
\hline \multirow[t]{2}{*}{ Laboratory parameters } & \multirow[t]{2}{*}{ Product } & \multicolumn{2}{|c|}{ Baseline } & \multicolumn{2}{|l|}{ Day 8} & \multicolumn{2}{|c|}{ Day 29} & \multicolumn{2}{|c|}{ Day 60} \\
\hline & & Mean & SD & Mean & SD & Mean & SD & Mean & $\mathrm{SD}$ \\
\hline \multirow[t]{2}{*}{ Red rood cells $(\times 10 \mathrm{E} 12 / 1)$} & $\mathrm{F}$ & 4.8 & 0.3 & 4.9 & 0.4 & 4.9 & 0.4 & 4.9 & 0.4 \\
\hline & $\mathrm{NF}$ & 4.9 & 0.3 & 4.9 & 0.4 & 5 & 0.4 & 4.9 & 0.3 \\
\hline \multirow[t]{2}{*}{ Haemoglobin (g/l) } & $\mathrm{F}$ & 14.1 & 1 & 14.2 & 1.2 & 14 & 1.1 & 14.1 & 1.1 \\
\hline & $\mathrm{NF}$ & 14.2 & 1.1 & 14.2 & 1.1 & 14.3 & 1 & 14.1 & 1.2 \\
\hline \multirow[t]{2}{*}{ Haematocrit (\%) } & $\mathrm{F}$ & 41.2 & 3.5 & 41.5 & 3.3 & 41.5 & 3.1 & 41.6 & 3.2 \\
\hline & NF & 41.8 & 2.6 & 41.5 & 3.2 & 42 & 3 & 41.7 & 3.2 \\
\hline \multirow[t]{2}{*}{ Platelets $(\times 10$ E9/1) } & $\mathrm{F}$ & 299 & 42 & 318.2 & 71.6 & 303.9 & 72.1 & 317.4 & 79.2 \\
\hline & NF & 304.1 & 84.7 & 314.3 & 68.5 & 294.9 & 68.2 & 315.3 & 79.2 \\
\hline \multirow[t]{2}{*}{ White Blood Cells $(\times 10$ E9/1) } & $\mathrm{F}$ & 6.7 & 1.3 & 6.8 & 2.1 & 6.8 & 1.2 & 7 & 1.8 \\
\hline & NF & 6.5 & 1.2 & 6.9 & 1.6 & 6.6 & 1.6 & 6.6 & 1.4 \\
\hline \multirow[t]{2}{*}{ Neutrophils $(\times 10 \mathrm{E} 9 / 1)$} & $\mathrm{F}$ & 3.7 & 0.9 & 3.7 & 1.8 & 3.7 & 1 & 3.9 & 1.3 \\
\hline & $\mathrm{NF}$ & 3.5 & 1.1 & 3.9 & 1.3 & 3.6 & 1.4 & 3.5 & 0.9 \\
\hline \multirow[t]{2}{*}{ Alanine transaminase (U/1) } & $\mathrm{F}$ & 30.7 & 26.6 & 34.4 & 32.5 & 32.8 & 34.8 & 29.7 & 31.8 \\
\hline & $\mathrm{NF}$ & 22.5 & 19.2 & 19.5 & 12.6 & 20.7 & 10.5 & 31.7 & 21.3 \\
\hline \multirow[t]{2}{*}{ Aspartic transaminase (U/l) } & $\mathrm{F}$ & 28.9 & 12.1 & 27.5 & 11.2 & 27.7 & 13.2 & 26.3 & 13.7 \\
\hline & NF & 22.3 & 9.3 & 25 & 13.3 & 22.8 & 4.9 & 26.7 & 10.2 \\
\hline \multirow[t]{2}{*}{ Alkaline phosphatase (U/l) } & $\mathrm{F}$ & 80.1 & 12.1 & 79.1 & 17.1 & 74.7 & 17.9 & 74.7 & 15.2 \\
\hline & $\mathrm{NF}$ & 69.5 & 14.4 & 70.7 & 15.7 & 75.7 & 15 & 75.6 & 15.5 \\
\hline \multirow[t]{2}{*}{ Calcium (nmol/l) } & $\mathrm{F}$ & 2.4 & 0.1 & 2.4 & 0.2 & 2.4 & 0.1 & 2.5 & 0.1 \\
\hline & $\mathrm{NF}$ & 2.4 & 0.1 & 2.4 & 0.1 & 2.5 & 0.1 & 2.4 & 0.1 \\
\hline \multirow[t]{2}{*}{ Potassium (nmol/1) } & $\mathrm{F}$ & 4 & 0.4 & 4.1 & 0.4 & 4.1 & 0.3 & 4.1 & 0.3 \\
\hline & $\mathrm{NF}$ & 4 & 0.4 & 4.3 & 0.6 & 4 & 0.2 & 4.1 & 0.3 \\
\hline \multirow[t]{2}{*}{ Sodium (nmol/1) } & $\mathrm{F}$ & 140.7 & 2.7 & 136.5 & 1.8 & 137.9 & 2.1 & 141.7 & 1.6 \\
\hline & $\mathrm{NF}$ & 139.6 & 2.7 & 137.2 & 3.6 & 137.8 & 2.3 & 141.1 & 1.7 \\
\hline \multirow[t]{2}{*}{ Uric acid $(\mathrm{mmol} / \mathrm{l})$} & $\mathrm{F}$ & 361.8 & 64.6 & 361.8 & 74.6 & 357.4 & 80.5 & 345.1 & 53.7 \\
\hline & $\mathrm{NF}$ & 352.2 & 46 & 353.9 & 56.4 & 358.4 & 55.1 & 347.8 & 54.1 \\
\hline \multirow[t]{2}{*}{ Creatinine $(\mathrm{mmol} / \mathrm{l})$} & $\mathrm{F}$ & 104.5 & 13.1 & 107.4 & 13.1 & 102.2 & 11.4 & 103.3 & 12.2 \\
\hline & $\mathrm{NF}$ & 102.3 & 12.5 & 99.9 & 10.1 & 103.9 & 11.2 & 104.6 & 12.6 \\
\hline
\end{tabular}

NF, Non-fixed combination; F, fixed combination 
It is important to appreciate that the tested hypothesis is stated as the "alternative" hypothesis; the null hypothesis is rejected in favour of the alternative hypothesis if there is sufficient statistical evidence against the null hypothesis. With the Schuirmann two one-sided tests, this is broken down into two one-sided hypotheses (above and below the allowed range), and two separate $t$ tests are applied. For two products to be considered bioequivalent, the null hypothesis of bioinequivalence must be rejected (the test must be significant, normally with $\alpha=0.05$ ).

In general, the metrics we obtained with the fixed combination were well within the variance of the nonfixed combination. However, the strict criteria of bioequivalence were not met entirely. The mean geometric mean ratios for the AUCs obtained with the fixed versus nonfixed were 92 and $86 \%$ for total DHA and DEAQ, respectively; when the individual subjects' AUC were compared, the corresponding mean values were 102 and $107 \%$, respectively. The $90 \% \mathrm{CI}$ around the geometric least squares means ratios of the AUC with the fixed product over the non-fixed formulation were within the upper bound, but below the lower bound (78 and $62 \%$ for total DHA and DEAQ, respectively). The two products generated similar AS/DHA and AQ/DEAQ plasma-time profiles, but inter-subject variability, as expected, was wide, and this may have affected our interpretation of the results.

Despite not meeting the defined criteria for bioequivalence, certain elements indicate that the two formulations do behave in a similar way: no significant difference was seen in the AUC ratios (AS:DHA and AQ:DEAQ) or the MRT of the individual parent compounds and metabolites between the fixed and non-fixed formulation. The AUC above the inhibitory concentration is conceivably the best predictor of antimalarial efficacy for both a drug with a long residence time such as AQ/DEAQ, and short-lived drugs, such as AS/DHA, while $\mathrm{C}_{\max }$ versus inhibitory concentration may also be of some value for the latter. Here, the $\mathrm{C}_{\max }$ of total DHA obtained with a single $200 \mathrm{mg}$ dose was 802 (range 270-2179) and $1077 \mathrm{ng} / \mathrm{ml}$ (range $348-3300 \mathrm{ng} / \mathrm{ml}$ ) with the fixed and non-fixed combination, respectively. Even the lowest values obtained were approximately 170 - and 20 -fold higher than the mean half maximal inhibitory concentration $\left(\mathrm{IC}_{50} ; 1.62 \mathrm{ng} / \mathrm{ml}\right.$; upper 95\% CI: $13.1 \mathrm{ng} / \mathrm{mL}$ ) of Plasmodium falciparum parasites from the Thai-Burmese border, respectively [4]. A note of caution should be introduced, however, when extrapolating from in vitro data to in vivo situations, particularly for the artemisinin-type compounds. While clinical failures to artemisinins are being reported from Western Cambodia [19], there is no clear association with increased $\mathrm{IC}_{50} \mathrm{~s}$, and the in vitro test as customarily performed may not be ideal for this type of compound.
The major question, then, is whether this lack of strictly defined bioequivalence is clinically relevant in patients. Comparison with biological data indicates that these differences are not expected to alter clinical responses in patients. Indeed, looking at available clinical data, a randomised controlled trial with a non-inferiority design comparing the loose and fixed-dose combinations has found similar efficacy rates for both combinations in paediatric falciparum malaria in Burkina-Faso [20]. The $80-125 \%$ limits for bioequivalence should also be based on the therapeutic window and pharmacokinetic/pharmacodynamic characteristics of a drug and should thus consider safety as well as efficacy [17]. For both drugs, and particularly AQ, which may have an increased risk of toxicity with higher doses [21, 22], exposure with the fixed formulation is well within the upper limit of acceptance. It should also be noted that the dose of AQ in the non-fixed combination was $13 \%$ higher than that in the fixed combination owing to different tablet strengths and that the data were not normalised by body weight in these analyses.

Irrespective of the discussion concerning the bioequivalence of the fixed and non-fixed formulation of AQ and AS, this study still adds to the currently limited information on the disposition of AQ. Two recent studies have reported considerably different pharmacokinetic characteristics of AQ [23, 24]. These differences, however, could be ascribed to different subject populations, disease effect and analytical assays: one study measured DEAQ in children with malaria from Papua New Guinea treated with AQ $(10 \mathrm{mg} / \mathrm{kg})$ for 3 days [23]; the other study investigated South African adult healthy volunteers given a single dose of AQ alone $(10 \mathrm{mg} / \mathrm{kg})$ [24]. The South Africa paper also reported the effects of co-administering AS and AQ with a three-phase cross-over design. This co-administration resulted in an approximately $35 \%$ reduction of the AUC for both drugs. Exposure to AS + AQ (measured by $\mathrm{C}_{\max }$ and $\mathrm{AUC}$ ) in the South African volunteers was approximately one-third of that in our study. This difference does not seem to be related to the assay used, as the detection limit of the HPLC-ECD used in our study is higher than that of the liquid chromatography/mass spectrometry used in the South African study (LLOQ 20 and $5 \mathrm{ng} / \mathrm{ml}$, respectively). One possible explanation of this observation is that polymorphisms of the CYP2C8 enzyme could contribute to different rates of drug metabolism [25].

For AS + AQ and other currently available ACTs, the selection of combination treatment doses has been largely empirical, aiming to achieve the same doses as if given individually. The dose-response relationship for AS has been described [26], but there is currently very little information, especially in malaria patients, on the pharmacokinetic/pharmacodynamic properties of AQ or the AS + 
AQ combination. A recent study exploring data from children in Zanzibar and Papua New Guinea derived the population kinetics of DEAQ and found a significant but weak correlation between the levels of DEAQ on Day 7 and antimalarial efficacy [27].

In clinical trials of uncomplicated falciparum malaria, co-administration of AS + AQ has been shown to be more effective than AQ alone [28] and is generally effective across Africa, although with regional variations, depending on the sensitivity of the local parasite strains to AQ [29]. Since the majority of these studies were conducted with individually formulated $\mathrm{AS}$ and $\mathrm{AQ}$, which were either the same products as those used here for reference or equivalent products, combining the two drugs into a single tablet can be expected to produce the same clinical results, given that the levels of exposure achieved in this study were similar.

With respect to AS, the main disposition parameters were similar to those of a previous study in Malaysian volunteers following a single oral dose of $200 \mathrm{mg}$ [30]. The AS + AQ combination was well tolerated, and only minor changes in safety parameters occurred, although the sample size was too small to detect rare events. In particular, there was no indication of liver or haematological toxicity, the two toxicities that have caused fatalities in the past when AQ was used as prophylaxis [31]. Although the number of healthy subjects was limited, each was exposed twice to AQ and followed for a long time. It has been suggested that repeat exposure to AQ may favour toxicity through the formation of a quinoneimine that may lead to immunoglobulin $\mathrm{G}$ immune-mediated liver and neutrophil toxicity. Asymptomatic, self-resolving hepatitis was reported in a healthy female subject in the South African study [32]. Clinicians should be wary of this possibility in clinical practice.

With the wider use of the new fixed-dose AS + AQ combination, further studies on the disposition of these compounds in malaria patients are warranted, and safety should continue to be monitored.

Acknowledgments This study was funded by the Drugs for Neglected Diseases initiative (DNDI) with the contribution of a European Union INCO/DEV grant. We wish to thank the participating volunteers and Ann-Marie Sevscik for editing the manuscript.

Disclaimer P. Olliaro is a staff member of the World Health Organisation. The author alone is responsible for the views expressed in this publication, and they do not necessarily represent the decisions, policy, or views of the World Health Organisation.

Roles of authors The authors have full control of all primary data and agree to allow the European Journal of Clinical Pharmacology to review their data if requested.

- V. Navaratnam was the Principal Investigator of the study. He contributed to the concept, protocol, analysis, and reporting of the study as well as the preparation of the manuscript.
- S. Ramanathan contributed personally to the study design and conducted the pharmacokinetic analyses

- M. Suhaimi Ab. Wahab participated in designing the concept and protocol of the study and supervised the clinical study conduct. He contributed personally to the treatment and follow-up of subjects.

- G. Siew Hua contributed personally to the treatment and follow-up of subjects.

- S. Mahsufi Mansor contributed to the supervision of the bioanalysis of samples.

- J-R.Kiechel contributed to concept of the project and critically reviewed the reporting of results.

- M. Vaillant designed and conducted analyses and contributed to the preparation of the manuscript.

- W.R.J. Taylor contributed to the clinical and safety-related aspects of protocol development, monitored the study and critically reviewed the manuscript.

- P. Olliaro contributed to the concept of the project, design of the protocol and analyses, reporting of the study and to the preparation of the manuscript.

Open Access This article is distributed under the terms of the Creative Commons Attribution Noncommercial License which permits any noncommercial use, distribution, and reproduction in any medium, provided the original author(s) and source are credited.

\section{References}

1. World Health Organisation (2008) World Malaria Report 2008 WHO/ HTM/MAL/2008.1 World Health Organisation, Geneva. Available at: http://www.who.int/malaria/wmr2008/. Cited 12 Feb 2009

2. World Health Organisation (2006) Guidelines for the treatment of malaria. WHO/HTM/MAL/2006.1108. World Health Organisation, Geneva. Available at: http://www.who.int/malaria/docs/ TreatmentGuidelines2006.pdf. Cited 17 July 2008.

3. White NJ, Olliaro PL (1996) Strategies for the prevention of antimalarial drug resistance: rationale for combination chemotherapy for malaria. Parasitol Today 12:399-401

4. Brockman A, Price RN, van Vugt M, Heppner DG, Walsh D, Sookto P, Wimonwattrawatee T, Looareesuwan S, White NJ, Nosten F (2000) Plasmodium falciparum antimalarial drug susceptibility on the north-western border of Thailand during five years of extensive use of artesunate-mefloquine. Trans R Soc Trop Med Hyg 94:537-544

5. Khanh NX, de Vries PJ, Ha LD, van Boxtel CJ, Koopmans R, Kager PA (1999) Declining concentrations of dihydroartemisinin in plasma during 5-day oral treatment with artesunate for Falciparum malaria. Antimicrob Agents Chemother 43:690-692

6. Newton PN, van Vugt M, Teja-Isavadharm P, Siriyanonda D, Rasameesoroj M, Teerapong P, Ruangveerayuth R, Slight T, Nosten F, Suputtamongkol Y, Looareesuwan S, White NJ (2002) Comparison of oral artesunate and dihydroartemisinin antimalarial bioavailabilities in acute Falciparum malaria. Antimicrob Agents Chemother 46:1125-1127

7. Newton P, Suputtamongkol Y, Teja-Isavadharm P, Pukrittayakamee S, Navaratnam V, Bates I, White N (2000) Antimalarial bioavailability and disposition of artesunate in acute Falciparum malaria. Antimicrob Agents Chemother 44:972-977

8. Suputtamongkol Y, Newton PN, Angus B, Teja-Isavadharm P, Keeratithakul D, Rasameesoraj M, Pukrittayakamee S, White NJ (2001) A comparison of oral artesunate and artemether antimalarial bioactivities in acute Falciparum malaria. $\mathrm{Br} \mathrm{J}$ Clin Pharmacol 52:655-661 
9. Li XQ, Björkman A, Andersson TB, Ridderström M, Masimirembwa $\mathrm{CM}$ (2002) Amodiaquine clearance and its metabolism to Ndesethylamodiaquine is mediated by CYP2C8: a new high affinity and turnover enzyme-specific probe substrate. J Pharmacol Exp Ther 300:399-407

10. Winstanley PA, Simooya O, Kofi-Ekue JM, Walker O, Salako LA, Edwards G, Orme ML, Breckenridge AM (1990) The disposition of amodiaquine in Zambians and Nigerians with malaria. Br J Clin Pharmacol 29:695-701

11. Pussard E, Verdier F, Faurisson F, Scherrmann JM, Le Bras J, Blayo MC (1987) Disposition of monodesethylamodiaquine after a single oral dose of amodiaquine and three regimens for prophylaxis against Plasmodium falciparum malaria. Eur J Clin Pharmacol 33:409-414

12. Winstanley PA, Edwards G, Orme ML, Breckenridge AM (1987) Effect of dose size on amodiaquine pharmacokinetics after oral administration. Eur J Clin Pharmacol 33:331-333

13. Navaratnam V, Mordi MN, Mansor SM (1997) Simultaneous determination of artesunic acid and dihydroartemisinin in blood plasma by high-performance liquid chromatography for application in clinical pharmacological studies. J Chromatogr B Biomed Sci Appl 692:157-162

14. Rowland M, Tozer T (1989) Clinical pharmacokinetics: concepts and applications, 2nd edn. Lea \& Febiger, Philadelphia

15. Statistical Solutions (1998) EquivTest1.0 user reference. Statistical Solutions, Cork, Ireland

16. U.S. Department of Health and Human Services, Food and Drug Administration, Center for Drug Evaluation and Research (2001) Guidance for industry: statistical approaches to establishing bioequivalence. U.S. Food and Drug Administration, Center for Drug Evaluation and Research, Washington D.C. Available at: http://www. fda.gov/cder/Guidance/3616fnl.pdf. Cited 17 July 2008

17. Committee for Proprietary Medicinal Products (2001). Note for guidance on the investigation of bioavailability and bioequivalence. The European Agency for the Evaluation of Medicinal Products, Basel. Available at: http://www.emea.europa.eu/pdfs/ human/qwp/140198en.pdf. Cited 17 July 2008

18. Teja-Isavadharm P, Peggins JO, Brewer TG, White NJ, Webster HK, Kyle DE (2004) Plasmodium falciparum-based bioassay for measurement of artemisinin derivatives in plasma or serum. Antimicrob Agents Chemother 48:954-960

19. Noedl H, Se Y, Schaecher K, Smith BL, Socheat D, Fukuda MM (2001) Artemisinin Resistance in Cambodia 1 (ARC1) Study Consortium. Evidence of artemisinin-resistant malaria in western Cambodia. N Engl J Med 359(24):2619-2620

20. Sirimi et al; Submitted to

21. Brasseur P, Agnamey P, Gaye O, Vaillant M, Taylor WR, Olliaro PL (2007) Efficacy and safety of artesunate plus amodiaquine in routine use for the treatment of uncomplicated malaria in Casamance, southern Sénégal. Malar J 6:150
22. Brasseur P, Agnamey P, Gaye O, Cisse M, Badiane M, Vaillant M, Taylor WR, Olliaro P (2009) Dosing accuracy of artesunate and amodiaquine as treatment for falciparum malaria in Casamance, Senegal. Trop Med Int Health 14(1):79-87

23. Hombhanje FW, Hwaihwanje I, Tsukahara T, Saruwatari J, Nakagawa M, Osawa H, Paniu MM, Takahashi N, Lum JK, Aumora B, Masta A, Sapuri M, Kobayakawa T, Kaneko A, Ishizaki T (2005) The disposition of oral amodiaquine in Papua New Guinean children with Falciparum malaria. $\mathrm{Br} \mathrm{J}$ Clin Pharmacol 59:298-301

24. Orrell C, Little F, Smith P, Folb P, Taylor W, Olliaro P, Barnes KI (2008) Pharmacokinetics and tolerability of artesunate and amodiaquine alone and in combination in healthy volunteers. Eur J Clin Pharmacol 64:683-690

25. Parikh S, Ouedraogo JB, Goldstein JA, Rosenthal PJ, Kroetz DL (2007) Amodiaquine metabolism is impaired by common polymorphisms in CYP2C8: implications for malaria treatment in Africa. Clin Pharmacol Ther 82:197-203

26. Angus BJ, Thaiaporn I, Chanthapadith K, Suputtamongkol Y, White NJ (2002) Oral artesunate dose-response relationship in acute Falciparum malaria. Antimicrob Agents Chemother 46:778782

27. Hietala SF, Bhattarai A, Msellem M, Roshammar D, Ali AS, Stromberg J, Hombhanje FW, Kaneko A, Bjorkman A, Ashton M (2007) Population pharmacokinetics of amodiaquine and desethylamodiaquine in pediatric patients with uncomplicated Falciparum malaria. J Pharmacokinet Pharmacodyn 34:669-686

28. Adjuik M, Agnamey P, Babiker A, Borrmann S, Brasseur P, Cisse M, Cobelens F, Diallo S, Faucher JF, Garner P, Gikunda S, Kremsner PG, Krishna S, Lell B, Loolpapit M, Matsiegui PB, Missinou MA, Mwanza J, Ntoumi F, Olliaro P, Osimbo P, Rezbach P, Some E, Taylor WR (2002) Amodiaquine-artesunate versus amodiaquine for uncomplicated Plasmodium falciparum malaria in African children: a randomized multicentre trial. Lancet 359:1365-1370

29. Olliaro P, Vaillant M, Phalkey R, Guthmann JP, Dorsey G, Brasseur P, D'Alessandro U, Millet P, Taylor WRJ (2006) Artesunate + amodiaquine (AS $+\mathrm{AQ}$ ) for the treatment of uncomplicated falciparum malaria: an inventory and systematic review of safety and efficacy data. Presented at 12th Int Soc Infect Dis. Lisbon, Portugal, pp. 15-18

30. Navaratnam V, Mansor SM, Mordi MN, Akbar A, Abdullah MN (1998) Comparative pharmacokinetic study of oral and rectal formulations of artesunic acid in healthy volunteers. Eur J Clin Pharmacol 54:411-414

31. Taylor WR, White NJ (2004) Antimalarial drug toxicity: a review. Drug Saf 27:25-61

32. Orrell C, Taylor WR, Olliaro P (2001) Acute asymptomatic hepatitis in a healthy normal volunteer exposed to 2 oral doses of amodiaquine and artesunate. Trans R Soc Trop Med Hyg 95:517-518 